\title{
The First Space-Related Study of a Kombucha Multimicrobial Cellulose- Forming Community: Preparatory Laboratory Experiments
}

O. Podolich $1, *$

Phone +380445265596

Email podololga@ukr.net

I. Zaets 1

O. Kukharenko 1

I. Orlovska

O. Reva 2

L. Khirunenko 3

M. Sosnin 3
A. Haidak 4
S. Shpylova 1
I. Rohutskyy 3
A. Kharina 4
M. Skoryk 5
M. Kremenskoy 5
D. Klymchuk 6

R. Demets 7

J.-P. de Vera 8 
N. Kozyrovska 1

${ }^{1}$ Institute of Molecular Biology and Genetics of NASU, Acad. Zabolotnoho str., 150, 03680 Kyiv, Ukraine

2 Bioinformatics and Computational Biology Unit, Department of Biochemistry, University of Pretoria, Pretoria, South Africa

3 Institute of Physics of NASU, Kyiv, Ukraine

4 Institute of Biology, Kyiv National Taras Shevchenko

University, Kyiv, Ukraine

5 NanoTechMed LLC, Kyiv, Ukraine

6 Institute of Botany of NASU, Kyiv, Ukraine

7 ESA/ESTEC, Noordwijk, The Netherlands

8 German Aerospace Center (DLR) Berlin, Institute of Planetary Research, Berlin, Germany

\section{Abstract}

Biofilm-forming microbial communities are known as the most robust assemblages that can survive in harsh environments. Biofilm-associated microorganisms display greatly increased resistance to physical and chemical adverse conditions, and they are expected to be the first form of life on Earth or anywhere else. Biological molecules synthesized by biofilm -protected microbiomes may serve as markers of the nucleoprotein life. We offer a new experimental model, a kombucha multimicrobial culture (KMC), to assess a structural integrity of a widespread microbial polymer cellulose - as a biosignature of bacteria-producers for the multipurpose international project "BIOlogical and Mars Experiment (BIOMEX)", which aims to study the vitality of pro-and eukaryotic organisms and the stability of organic biomolecules in contact with minerals to analyze the detectability of life markers in the context of a planetary background. In this study, we aimed to substantiate the detectability of mineralized cellulose with 
spectroscopy and to study the KMC macrocolony phenotype stability under adverse conditions (UV, excess of inorganics etc.). Cellulose matrix of the KMC macrocolony has been mineralized in the mineral-water interface under assistance of KMC-members. Effect of bioleached ions on the cellulose matrix has been visible, and the FT-IR spectrum proved changes in cellulose structure. However, the specific cellulose band vibration, confirming the presence of $\beta(1,4)$-linkages between monomers, has not been quenched by secondary minerals formed on the surface of pellicle. The cellulose-based KMC macrocolony phenotype was in a dependence on extracellular matrix components (ionome, viriome, extracellular membrane vesicles), which provided its integrity and rigidness in a certain extent under impact of stressful factors.

\section{Keywords}

Biology and Mars Experiments (BIOMEX)

Kombucha

Biosignature

Biofilm

Bacterial cellulose

\section{Introduction}

In the search for signatures of life, biomarkers would include DNA (Maier et al. 2004; Thiel et al. 2011 ) and proteins or their components nucleobases and amino acids, respectively (Parnell et al. 2007). Other cellular products such as hopanoids (Simoneit et al. 1998), secondary metabolites, pigments or cell surface components (de Vera et al. 2012) seem also to be promising biomarkers. Non-invasive in situ-probing of biomass of microbial communities or bioorganic and inorganic deposits may be sufficient for detection with sensitive instruments like Infrared spectroscopy (Igisu et al. 2006), Raman spectroscopy (de Vera et al. 2012), and mass-spectroscopy (Gudipati and Rui 2012).

A promising approach in the search for traces of Earth-like life is also focused on the examination of surface and subsurface rock/dust material of meteorites, comets or the nearest Earth neighbors (McKay et al. 1996; 
Kebukawa et al. 2009; De Gregorio et al. 2013). For the remote detection of biosignatures, photosynthetic and non-photosynthetic pigments (Varnali and Edwards 2013; Hegdea et al. 2015; Schwieterman et al. 2015), biogenic gases from anoxygenic photosynthesis in microbial mats or other biosignature gases (Seager and Bains 2015) are new biosignatures of life which have been proposed by researches. One of the strategies for substantiation of the extraterrestrial life existence probability in the Universe is to investigate the stability of selected putative biosignatures in the extraterrestrial analog environments, e.g., within martian simulation chambers or under low Earth orbit in specially designed devices with Marslike atmosphere (de Vera et al. 2012).

The predominant form of life might be a microbial community enclosed in self-produced hydrated polymeric matrices - biofilms. This form of life thrives on a number of advantages, among which are nutrients in close proximity, enhanced genetic exchange, and increased tolerance towards environmental stressors (see rev. Flemming and Wingender 2010). The microorganisms within biofilms are more resistant to environmental stressors than the same microorganisms growing outside a biofilm as planktonic populations (Costerton et al. 1995; Welch et al. 2005).

Microbial cooperation in biofilm growth benefits the community in the harsh environment (Liu et al. 2015). Most likely, the first biofilm formations occurred on rocks in wet environments. In extraterrestrial environments, signs of life may be found within sites of colonization by the presence of microbial mats and biofilms. Microbial biofilms have also been suggested as refractory targets for the detection of fossilized extraterrestrial microbial organisms (Westall et al. 2000).

Extracellular polymeric substances, widely produced by microbes in biofilms for attachment and protection, are important in providing nucleation sites and facilitating sediment formation. An approach to identify signs of life on remote planets is to investigate and model possible changes of biomolecules, leading to formation of fossils (Noffke 2015). We offer an experimental model, a biofilm-forming kombucha microbial culture (KMC), to study the accumulation of diagenetically changed biomolecules, which may serve as promising life biosignatures of active or fossil microbial associations (Kukharenko et al. 2012; Zaets et al. 2014). KMC is a robust assemblage of bacteria and yeasts that exists within the cellulose-based 
pellicle biofilm (see rev. Jayabalan et al. 2014). The hydrated biofilm protects microbial cells from adverse factors like ultraviolet radiation (Ross et al. 1991) or high-hydrostatic pressure (Kato et al. 2007). Bacterial cellulose $(\mathrm{BC})$ forms a $3 \mathrm{D}$ structure for pellicle, a harbor for the community cells. $\mathrm{BC}$ is known as a stable robust exopolysaccharide polymer macromolecule, which is produced by a wide range of bacterial species from various microenvironments (mats, soil, hot springs, plants, etc. (Romling 2002).

Bacteria produce two forms of cellulose, cellulose I and cellulose II (Chawla et al. 2009). Cellulose I is a ribbon-like polymer composed of bundles of microfibrils, while cellulose II is an amorphous polymer that is thermodynamically more stable than cellulose I (Yu and Atalla 1996). The crystallinity of $\mathrm{BC}$ is higher than of plant cellulose, and this results in higher thermal stability. Being one hundred times thinner than cellulose of fibrils obtained from plants, BC possesses high tensile strength. Such a peculiar super-molecular structure engineered by nature has become to be stable. The highly porous structure of the cellulose nanonetwork and controlled shape make BC attractive for new ultralight and stable nanomaterials manufacture (see review by Qiu and Netravali 2014), and various possibilities of the BC-polymer modifications open the unrestricted development of new cellulose-based nanocomposites. In natural settings, the interactions with various inorganic and organic ions lead to changes in the polymer $\mathrm{BC}$ molecule during biogenic processes under the assistance of microbial organisms, inhabiting the biofilm. In addition, the communitylevel microbial interactions, such as sharing of produced metabolites and defense, result in the modification of the $3 \mathrm{D}$ cellulose-based hub (Lee et al. 2014).

In the first pre-flight study, we were focused on the substantiation of the $\mathrm{BC}$ as a robust biomarker for life signs detection before starting our investigations in the planetary analog environment as planned in the frames of BIOMEX. This means more specifically, we analyzed its detectability with FT-IR-spectrometry after the matrix mineralization and we investigated the BC structural integrity after irradiation with low-dose UV and high-speed electrons. We wanted to understand whether contact with rocky material would change diagenetically a polymer molecule so as to be recognized via its spectra, or the cellulose mineralization would be an obstacle in its detection. We also studied the effect of extracellular 
components on the BC-based biofilm integrity. Here, we present modeling results of the short-term mineralization of bacterial cellulose in the presence of the anorthosite rock under assistance of model KMC.

\section{Materials and Methods}

\section{Microorganisms}

The kombucha microbial culture Medusomyces gisevii Lindau, Komagataeibacter intermedius IMBG180 were obtained from the collection of microorganisms of the Institute of Molecular Biology and Genetics (Kyiv, Ukraine). It was maintained in a filter sterilized black tea (Lipton, $1.2 \%, w / v)$ with white sugar $(3 \%, w / v)$ (BTS) at $28{ }^{\circ} \mathrm{C}$.

\section{Cultural Media and Cultivation Conditions}

For bacteria culturing, nutrient media A, LB (Miller 1972) and HS (Hestrin and Schramm 1954) were used. For yeast culturing, Glucose Yeast Peptone medium (HiMedia Laboratories, India) was used. Antibiotics cyclohexymide (100 $\mu \mathrm{g} / \mathrm{ml}$, Sigma-Aldrich) against yeasts and cephtriaxon $(50 \mu \mathrm{g} / \mathrm{ml}$, Roche Biochemicals) against bacteria were applied.

\section{Geological Sample}

Anorthosite rock samples were obtained from the Penizevitchi deposit (Ukraine) (Mytrokhyn et al. 2008). Rocks were fragmented in particles of $0.1-1 \mathrm{~mm}$, sterilized by autoclaving at $120^{\circ} \mathrm{C}$ for $40 \mathrm{~min}$, and then added to $\mathrm{KMC}$ culture as an additive $(20.0 \%)$.

\section{Isolation of Cultivable Forms of KMC-Members Entrapped in the Cellulose-Based Biofilm}

For isolation of microorganisms, $1 \mathrm{~g}$ of wet KMC pellicle was homogenized in a sterile mortar with $0.2 \mathrm{ml}$ of $0.9 \% \mathrm{NaCl}$. The homogenate was serially diluted in the same solution and spread on selective media with appropriate antibiotics (see p. 2.2).

\section{Microbial Species Identification by Phenotype and Genotype}

The cultivable kombucha community members were identified by morphological features (Brenner 1997) and proved by sequencing and 
analysis of the PCR products of marker genes (16S rRNA for bacteria and 26S for yeasts) as described in (Reva et al. 2015).

\section{Randomly Amplified Polymorphic DNA Fingerprinting}

Total DNA samples from treated and untreated with anorthosite KMC were isolated using innuSPEED Bacteria / Fungi DNA isolation kit (Analytik Jena AG). The nucleic acids were quantified and qualified by NanoDrop ND-1000 spectrophotometer (NanoDrop Technologies, Wilmington, DE). Two RAPD primers: OPO10 (5'-TCAGAGCGCC-3') for proteobacteria (Lee et al. 2012) and OPX-03 (5'-TGGCGCAGTG-3') for yeasts (Echeverrigaray et al. 2000) were chosen for amplifying kombucha microbial DNA in the experiment as it provided reproducible and discriminatory banding patterns. The PCR mixture consisted of $100 \mathrm{ng}$ microbial genomic DNA, $2.0 \mu 1$ 10x PCR buffer with $20 \mathrm{mM} \mathrm{MgCl} 2,2.0 \mu 1$ $10 \mathrm{mMdNTPs}, 1 \mathrm{U}$ Taq polymerase, $20 \mathrm{pM}$ RAPD primer, and sterile ultrapure water was added to a final volume of $20 \mu \mathrm{l}$. The reaction was run for 40 cycles in the following condition: denaturation at $94{ }^{\circ} \mathrm{C}$ for $1 \mathrm{~min}$, annealing at $36{ }^{\circ} \mathrm{C}$ for $1 \mathrm{~min}$, and extension at $72{ }^{\circ} \mathrm{C}$ for $1 \mathrm{~min}$. An initial denaturation for $4 \mathrm{~min}$ at $95{ }^{\circ} \mathrm{C}$ and a final 7 min extension at $72{ }^{\circ} \mathrm{C}$ were applied. Products of the amplifications were resolved on $2.5 \%$ agarose gel, stained with ethidium bromide, and visualized under UV light. The gels were photographed and analyzed using PyElph 1.4 program. RAPD patterns were clustered using the unweighted pair-group method with arithmetic average (UPGMA).

\section{Biofilm Microscopic Analyses}

\section{Confocal Scanning Laser Microscopy (CSLM)}

Samples were fixed in the formaldehyde vapor during an hour and stained with calcofluor (excitation $405 \mathrm{~nm}$, filter BP 420-480), and thiazine dyes (excitation $514 \mathrm{~nm}$, filter BP 530-600 nm). A microscopic examination of sample fluorescence was performed, using CSLM AXIOSKOP - 2 ZEISS equipped by the LSM 510 PASCAL (CarlZeiss, FRG) software.

The Energy-Dispersive X-ray Spectra (EDXS) Microanalysis System

Scanned electron microscope Tescan Mira 3 LMU (Tescan s.r.o., Czech Republic) equipped with energy dispersive spectrometer (EDS/EDX) Oxford X-max $80 \mathrm{~mm}$ (Oxford Instrument, UK) controlled by Inca Energy 
analysis software was used to provide chemical elemental analysis. Samples of the studied biofilm $(5 \times 5 \mathrm{~mm})$ were placed on specimen mount and dried in microscope under low pressure.

\section{Fourier Transform InfraRed (FT-IR) Spectroscopy}

Infrared Fourier spectroscopy was used for assessment of structural differences in natural and encrusted cellulose-based matrices. Each cellulose sample was air-dried on a glass slide in the form of a thin film. The film thickness was $0.025-0.03 \mathrm{~mm}$. The IR absorption analysis was carried out, using a Bruker-113v Fourier Transform spectrometer. The measurements were performed at room temperature in the range $50-$ $4000 \mathrm{~cm}^{-1}$ with a spectral resolution of $1.0 \mathrm{~cm}^{-1}$.

\section{Bacteriophages and Outer Membrane Vesicles (OMV) Isolation}

Prophages were induced in the log-phase growing culture Komagataeibacter intermedius IMBG180 in HS medium with polychromatic UV. Medium pressure mercury vapor lamp (polychromatic light, 200-600 nm wavelengths) (Jelight Company, Inc) was used to irradiate the liquid cultures in open Petri dishes with a dose $10 \mathrm{~J} / \mathrm{m}^{2}$. After appropriate treatment, the culture was centrifuged at 10,000 rpm for $20 \mathrm{~min}$ at $4{ }^{\circ} \mathrm{C}$. The supernatant was collected and further ultra-centrifuged at $100,000 \mathrm{~g}$ for $1 \mathrm{~h}$ at $4{ }^{\circ} \mathrm{C}$ (Beckman Instruments Inc., L8M, rotor 55.2 Ti). The resulting pellet was re-suspended in sterile $0.9 \%$ saline.

\section{Bacteriophages and Membrane Vesicles Visualization}

Bacteriophage-like particles and OMV were viewed in samples by transmission electron microscope JEM-1400 (Jeol Inc., Japan). Formvar coated copper grids were dipped into sample and then contrasted with $2.0 \%$ solution of uranyl acetate within $30 \mathrm{~s}$ and grids were examined at 90,000 magnification at a voltage of $80 \mathrm{kV}$. Membrane vesicles isolated from KMC were viewed in samples by scanning electron microscope Mira 3 LMU (Tescan s.r.o., Czech Republic) using STEM detector in bright field mode at various magnifications and accelerating voltage of $10 \mathrm{kV}$. OMV size statistics and average derived count rate were measured using dynamic laser scattering (Zetasizer Nano ZS and Zetasizer software Malvern Instrumental Ltd). 


\section{Treatment of the Kombucha Culture with Polychromatic UV or High-Speed Electrons}

Medium pressure mercury vapor lamp (polychromatic light, 200-600 nm wavelengths) (Jelight Company, Inc) was used to irradiate the liquid cultures of KMC with anorthosite in open Petri dishes with a dose $10 \mathrm{~J} / \mathrm{m}^{2}$. Kombucha culture (a $1 \mathrm{ml}$ volume was arranged in a $1 \mathrm{~mm}$-width in a sterile plastic bag) was irradiated with high-speed electrons gained at the Argus accelerator in a dose of 2 and 5 Gy, $15 \mathrm{~s}$

\section{Treatment of Bacterial Cellulose Film with High-Speed Electrons}

Samples of dry cellulose-based kombucha pellicle were irradiated with $1 \mathrm{MeV}$ electron doses: $1.0 \times 10^{14} ; 5.0 \times 10^{14} ; 1.0 \times 10^{15} \mathrm{el} \cdot \mathrm{cm}^{-2}$. The fluencies with high-speed electrons gained at the Argus accelerator were selected to simulate the final dose of irradiation on the LEO.

\section{Statistical Tests}

The significance of differences between means from three samples were based on Student's $t$-test $(p<0.05)$.

\section{Results}

\section{Influence of Anorthosite-Derived Ions on Microbial Community Structure in a Water-Mineral System}

DNA metabarcoding revealed a complex and flexible structure of model $\mathrm{KMC}$, constituting more bacterial and yeast organisms in addition to those found by cultural method (Reva et al. 2015). Several pro- and eukaryotic microorganisms have been uncovered. The community comprised a core bacterial (Proteobacteria) and yeast (Ascomycota) phyla, and several other occasionally occurring micro-organisms were also identified. The community composition was dependent on the growth conditions, and occasional community members resuscitated from uncultivable state under nonconventional conditions. The cultivable fraction of the community included $\alpha$-proteobacterial acetobacteria of two genera - Komagataeibacter (former Gluconacetobacter) and Gluconobacter. Several yeast genera, belonging to Brettanomyces/Dekkera, Pichia (Issatchenkia), Zygosaccharomyces were isolated. 
Within the experiment on cellulose mineralization, KMC cultivated for 21 days in BTS supplemented with a significant amount of sterile anorthosite rock. The presence of anorthosite in BTS has changed the KMC composition of cultivable microbial forms. Thus, yeast strain Dekkera anomala has not been isolated. Viability of bacteria strains was not affected by the rock. In such microecosystems, the presence of metal ions generated from anorthosite rock may increase the total toxicity of cultural liquid, causing a reduction of microbial diversity (Johnson and Hallberg 2003 ).

Alternatively, along with selection of resistant microbial species, other community members might enter into VBNC (viable-but-nonculturable) state in order to survive (Ordax et al. 2006). Changes in uncultivable populations of KMC were detected using the DNA-dependent RAPD-PCR tool.

RAPD-PCR is a useful technique for studying changes in structure of microbial communities (Franklin et al. 1999; Li et al. 2012), which employs short primers of arbitrary sequences to amplify random portions of the sample DNA by PCR (Williams et al. 1990). Individuals that have different polymorphic DNA sequences have different annealing places for the same primer and produce different patterns of short DNA fragments. Two RAPD-PCR procedures were carried out to find any differences in total bacterial and yeast fractions of kombucha community. Dendrograms on Fig. 1 $\mathrm{a}$ and $\mathrm{b}$ show that a pattern of bacterial DNA from untreated KMC control in both phases (sessile cells in a pellicle film, Cf, and planktonic cells in a liquid phase, $\mathrm{Cp}$ ), as well as yeast, formed distinct clusters from cultures grown with anorthosite (Cfa, Cpa). This may mean that the presence of anorthosite in BTS has changed the KMC composition of both culturable and unculturable microbial forms.

\section{Fig. 1}

Cluster analysis of the yeast (a) and proteobacteria (b) communities by RAPD patterns, using the UPGMA clustering method. Cf control (biofilm), $C p$ control (cell precipitate), $C f a$ control with anorthosite (biofilm), Cpa control with anorthosite (cell precipitate) 


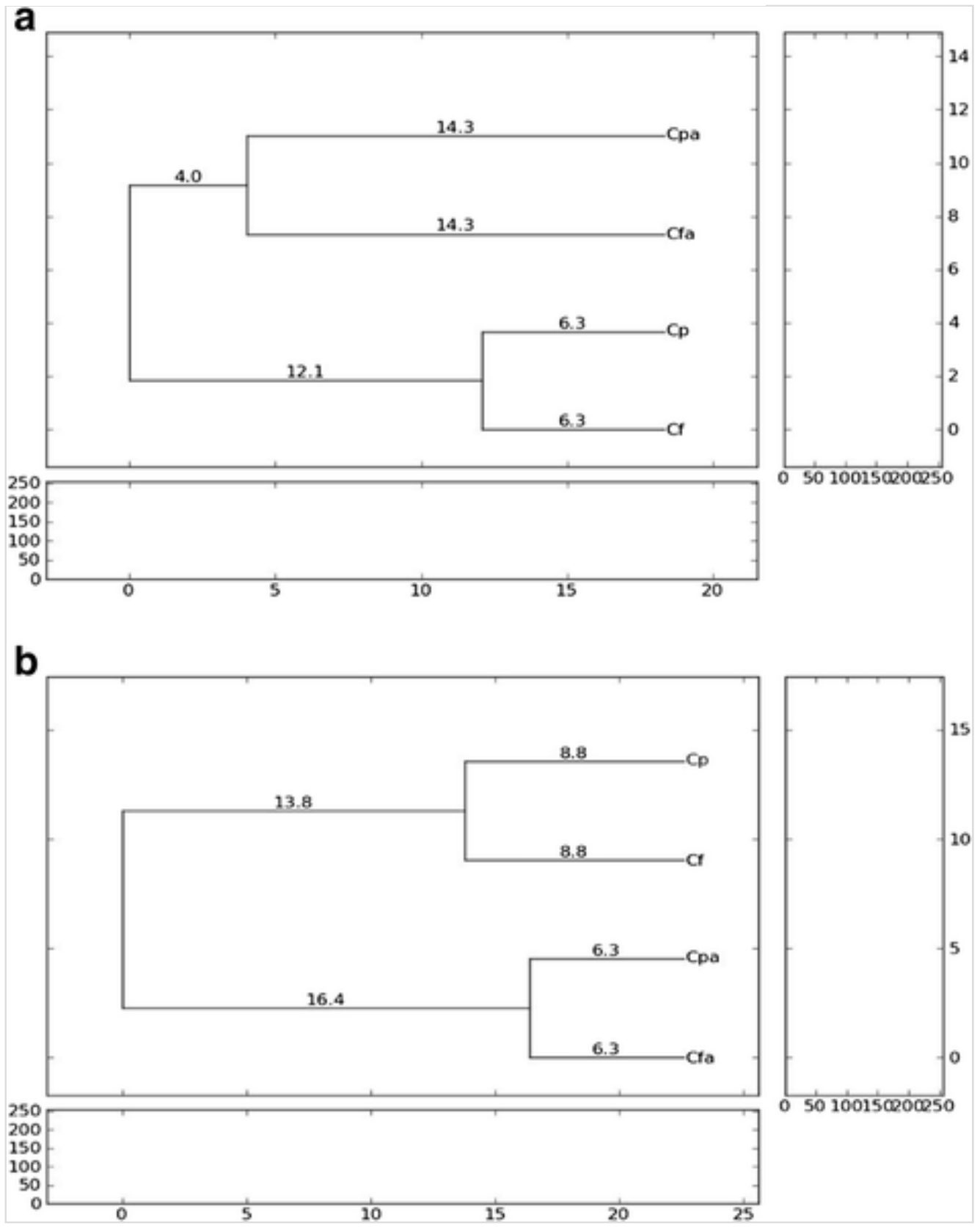

\section{Prophage Activation}

Phages may play an important role in the adaptation of microbiomes to stressful environments (Wang et al. 2010). About $70 \%$ of sequenced genomes contain prophages (Paul 2008). Short-wavelength UV irradiation and uptake of metals (e.g., iron) during biofilm formation may trigger phage-mediated lysis of a sub-population of cells (Binnenkade et al. 2014). To test this, a cellulose-producing culture $K$. intermedius, one of the key players in KMC, was treated with a dose $10 \mathrm{~J} / \mathrm{m}^{2}$ polychromatic UV. This procedure resulted in a partial lysis of the culture and in a formation of rare defective phage particles with morphology of Myoviridae (Fig. 2a). The latter was proven by bioinformatics tools (Kharina et al. 2015). In the ageing $\mathrm{KMC}$, rare defective bacteriophages also have been detected (Fig. 2b). The pellicle UV-damage was not complete, and under a short 
period of time the community and pellicle integrity was restored. However, there was no lysis/phage particle production within the $\mathrm{KMC} /$ anorthosite two-phase system under UV induction.

\section{Fig. 2}

Transmission electron micrographs, illustrating morphology of temperate bacteriophage detected in Komagateibacter intermedius IMBG180 after a treatment with polychromatic UV (a). A tailed bacteriophage has been found in the ageing kombucha culture with transmission electron microscopy (b). Scanning electron micrograph of a wide range of membrane vesicles isolated from kombucha microbial community (c)

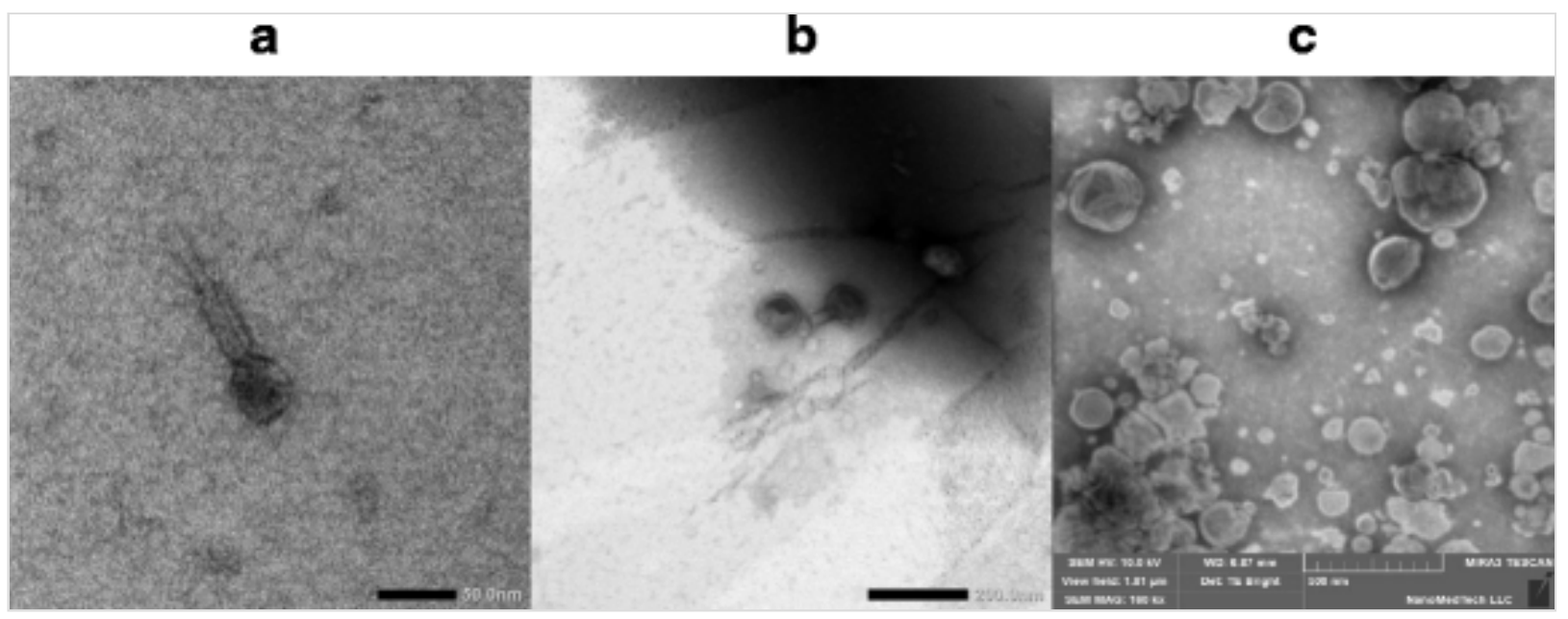

\section{Extracellular Membrane Vesicles Release}

A wide range of extracellular membrane vesicles (EMV) of sizes 30$1200 \mathrm{~nm}$ have been isolated from KMC (Fig. 2c). Total preparation of extracellular vesicles, including OMVs, post-Golgi vesicles (PGV) and microvesicles showed bell-shaped size distributions (Fig. 3a) with peaks of 180 and $220 \mathrm{~nm}$. Interestingly, in KMC grown with anorthosite, the range of size distribution of membrane vesicles was more narrow $(55-1055 \mathrm{~nm})$ than in the control variant (without anorthosite) $(35-1080 \mathrm{~nm})$ with the peak of $160 \mathrm{~nm}$ (Fig. 3b). Derived count rate in both variants showed that the total putative number of membrane vesicles produced by KMCmembers in the presence of anorthosite may exceed control (without anorthosite) in 20 times. The 16-fold increased amount of released vesicles has been detected after a low-dose high-speed electron irradiation (not shown). It is interesting to note that the average size of membrane vesicles produced by the stressed microbial cells (both mineralized and irradiated) was reduced from $180-220 \mathrm{~nm}$ to $124-160 \mathrm{~nm}$. 


\section{Fig. 3}

Size statistics of membrane vesicles produced by KMC in sugared tea (a) and sugared tea supplemented with anorthosite (b) (dilution 1:10). Average Derived Count Rate for A - 1166,0 for B - 24140, 0
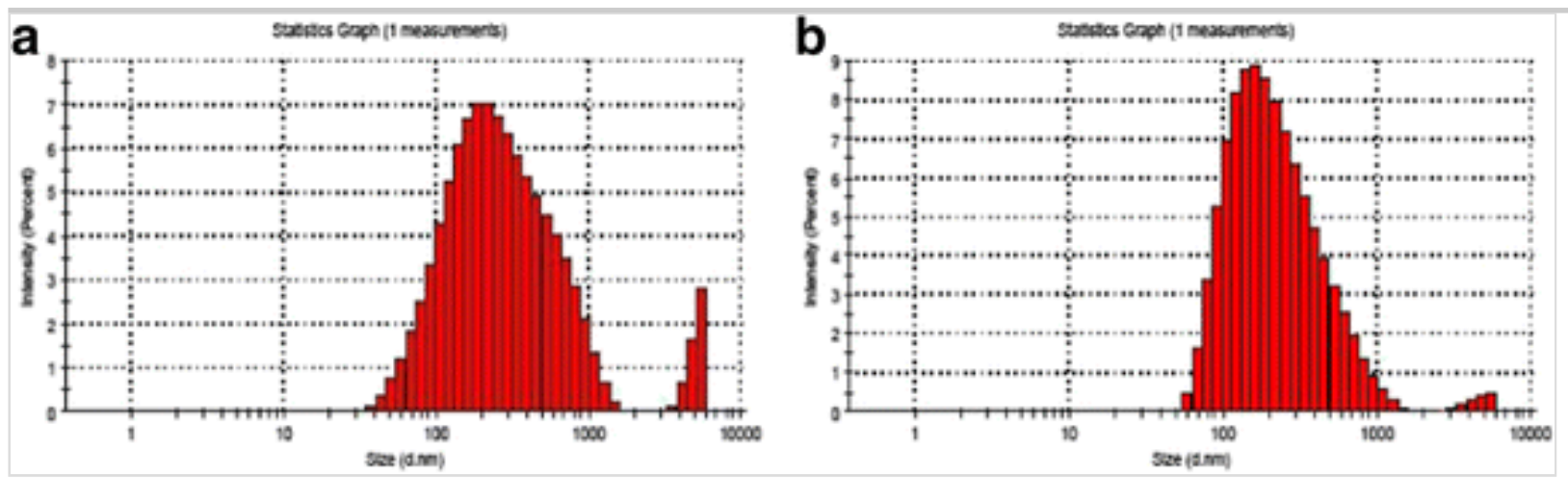

Biofilm formation may be affected by the presence of rock minerals, e.g., the high level of iron could disrupt biofilm formation (Musk et al. 2005). In this study, biofilm development was a bit impaired in the presence of anorthosite: the pellicle was thinner as compared to the biofilm produced by pristine $\mathrm{KMC}$, and its colour was getting grey because of bioleaching and accumulating of ions from the minerals, composing the anorthosite rock.

\section{Influence of Anorthosite on Biofilm Formation}

Microscopic Examination of the Mineralized Biofilm

On the bottom side of grey mineralized films, separate secondary mineral grains observed of 5.0-25.0 $\mu \mathrm{m}$ (Fig. $4 \mathrm{~b}$ and c). It should be noted that films did not have a direct contact with minerals pellet on the bottom of a cultivation reactor. There was a liquid kombucha culture between a layer of anorthosite at the bottom of the bioreactor and a cellulose-based pellicle, floating on the cultural liquid. Control cellulose-based pellicle grown in the absence of anorthosite was without visible mineral deposits (Fig. 4a).

\section{Fig. 4}

Confocal scanning laser microscopic image of microbial cellulose-based pellicle produced by kombucha in normal nutrient medium (sweetened tea) (a) and under excess of inorganics (anorthosite) in the medium (b, c). Proteins stained with thiazine (yellow signal), cellulose stained with 
calcofluor (blue signal). Scale bars equal $10 \mu \mathrm{m}$

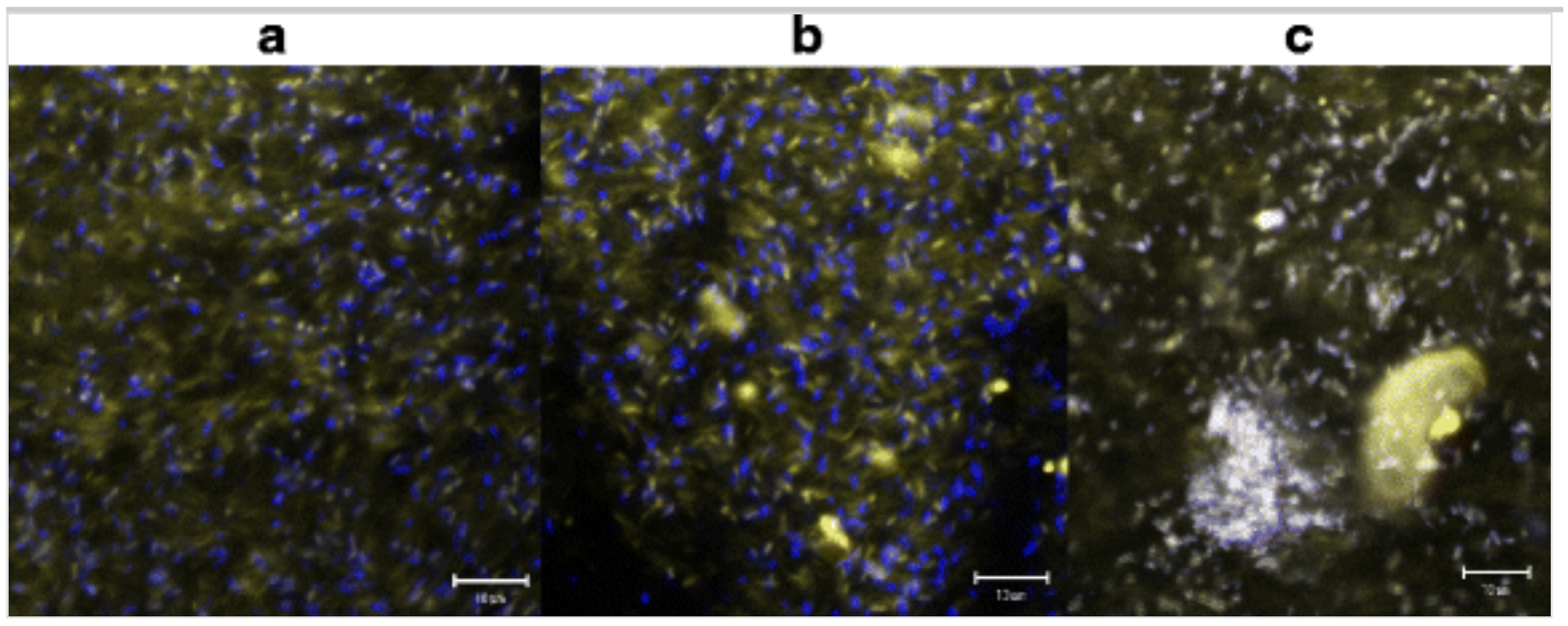

\section{EDX-ray Spectra Microanalysis of the BC-Based Membranes}

Colonization of the anorthosite by microorganisms caused the release of elements into aqueous phase of two-phase system and transfer them into the biofilm matrix. SEM-EDXS microanalysis was used to screen mineral components accumulated by $\mathrm{KMC}$ in $\mathrm{BC}$-membranes. Bottom side of the mineralized $\mathrm{BC}$-based membranes was covered with a layered crust, where separate mineral particles could be observed (Fig. 5a).

\section{Fig. 5}

SEM micrographs\& EDX spectra of secondary mineral aggregates on the bottom side of encrusted cellulose-based film (spectrum A) and pristine cellulose-based film (spectrum B) 

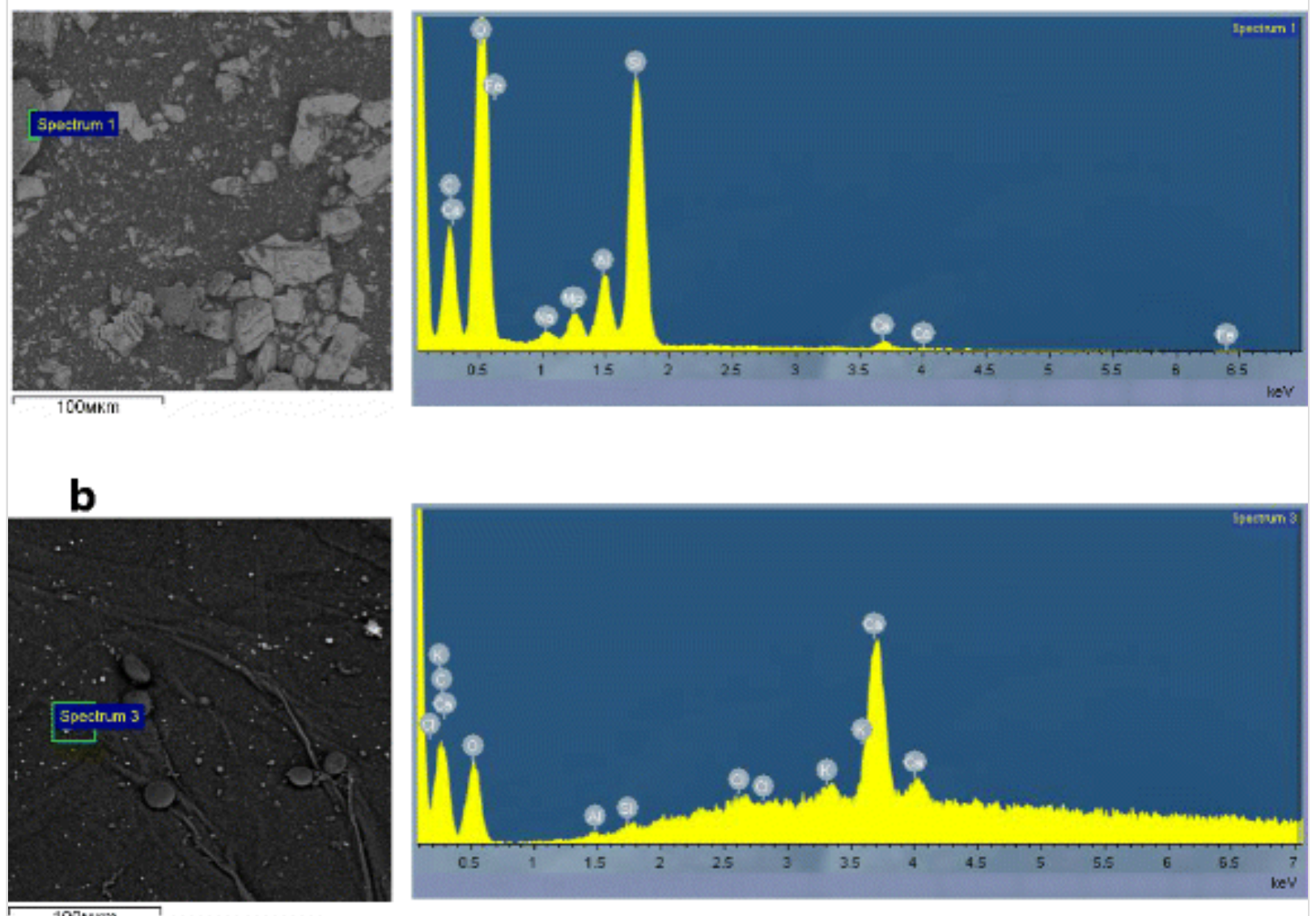

07 MKon

Increase of the $\mathrm{Al}, \mathrm{Si}, \mathrm{K}$ content in the biofilm produced by $\mathrm{KMC}$ grown with the anorthosite rock, as well as the appearance of $\mathrm{Fe}, \mathrm{Na}, \mathrm{Mg}$ showed a mobilization capacity of the community-members. Inorganic ions were bioleached from the rock by KMC-members and accumulated in/on the 3D cellulose-based web. Pristine BC membranes were inseminated with microbial cells and their conglomerates, and there were no mineral particles on the pellicle biofilm surface seen (Fig. 5b; see also Fig. 4a).

FT-IR Spectroscopic Analysis of BC After Mineralization and High Energy Electrons Irradiation

FT-IR spectroscopic analysis of mineralized BC in comparison with pristine $\mathrm{BC}$ helped us to investigate a character of interactions between $\mathrm{BC}$ and bioleached inorganics. The bacterial cellulose modification expected in the presence of aluminosilicate anorthosite, and it has been researched during a restricted period of time ( 21 days). Within this period, cellulose molecules produced in the presence of anorthosite had detectable changes as recorded by FT-IR spectroscopy (Fig. 6a). After absorption of inorganic ions there were differences, such as the intensity and half-width of the bands, position of some bands, and the appearance of new components in BC encrusted with anorthosite, a weakening of the band between 3000 and $3600 \mathrm{~cm}^{-1}$, 
corresponding to -OH stretching vibrations. Importantly, characteristic cellulose fingerprints were seen in the IR-spectrum of mineralized $\mathrm{BC}$ samples, e.g., a band at $897 \mathrm{~cm}^{-1}$, which confirms the presence of $\beta(1,4)$ linkages in polymer cellulose molecule.

\section{Fig. 6}

The FT-IR absorption spectra of a nonirradiated (a) and irradiated (b) with high-energy electrons biofilms produced by kombucha multimicrobial culture in the range of 50-4000 $\mathrm{cm}^{-1}$. a - natural (1) and cultured in the presence of anorthosite $(2,3)$ biofilms. b - irradiated $(a)$ and nonirradiated $(b)$ with highenergy electrons biofilms. A spectral resolution of $1.0 \mathrm{~cm}^{-1}$. The spectra are shifted on the vertical axis for clarity
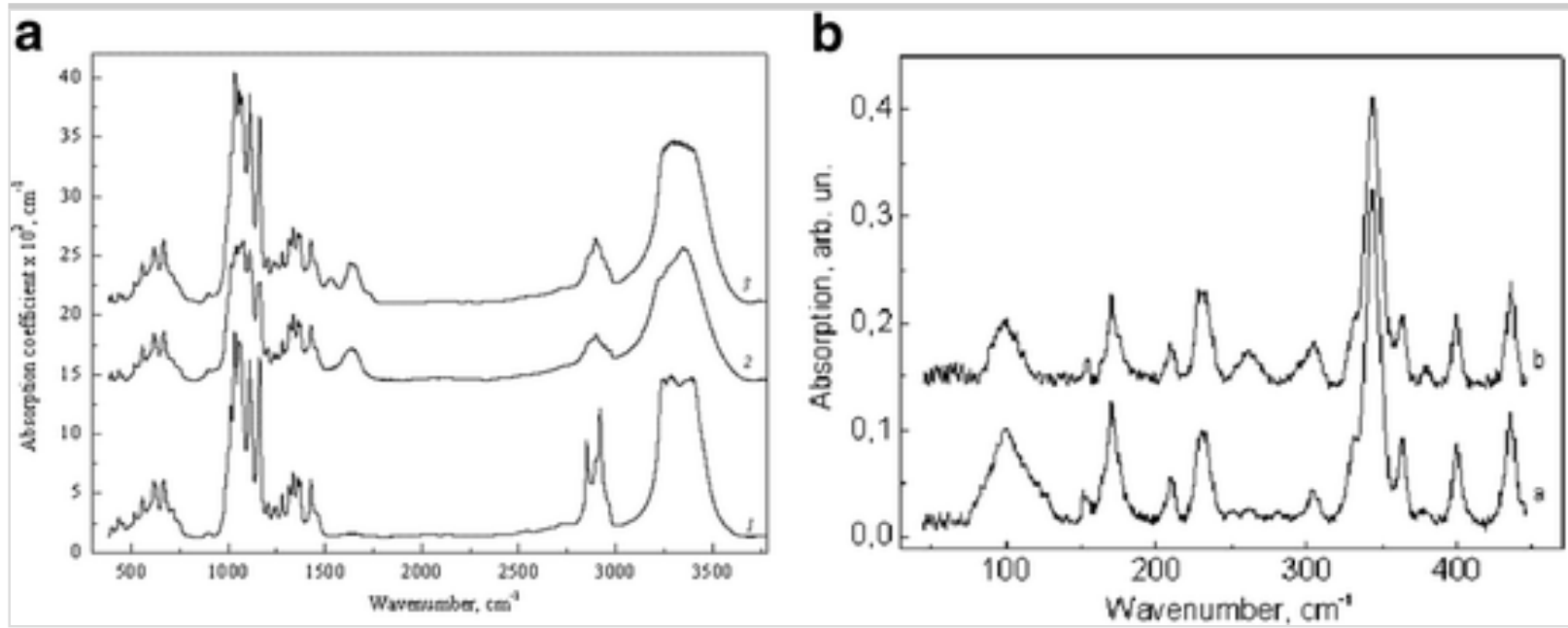

Within the sensitivity of the apparatus, there were practically no visible changes in the samples of irradiated with high energy electrons BC membranes in the range of $400-4000 \mathrm{~cm}^{-1}$, however, there were minor differences in the range of $50-450 \mathrm{~cm}^{-1}$ (Fig. 6b). More specifically, a new band of small intensity has been formed at $260.9 \mathrm{~cm}^{-1}$.

\section{Discussion}

Prehistoric forms of cellulose were synthesized by bacteria and cyanobacteria in order to survive in previous times. Cellulose is highly thermostable and more resistant to environmental factors than other biopolymers (Griffith et al. 2008). For this reason, it may be considered as a biosignature $\bar{\xi}$, however, new arguments should be added in a support of this suggestion. In particular, interacting with minerals in specific econiches, microorganisms may leach out chemical elements from them and mineralize cellulose, embedding it with bioleached ions and making this 
molecule less recognized.

\section{The Cellulose as a Putative Biosignature is a Component of a 3D Kombucha Pellicle Film}

Pellicle biofilms were first described by Ferdinand Cohn in 1876 as macrocolonies grown on the edge of liquid-air phases (Cohn 1876). The kombucha pellicle is a 3D hub for symbiotic microbial organisms and constitutes a complex of cellulose and other polysaccharides, proteins, exogenic DNA (eDNA), extracellular membrane vesicles, viruses, and inorganic inclusions, as well as microbial cells, which spread either systemically or localized in microcolonies. Within the hub, microbial organisms exist as social entities, building their relationships on, first of all, metabolic cooperation and defense strategies. The KMC macrocolony phenotype is in a strict dependence on extracellular matrix components, which provide its integrity and rigidness. A set of external stressors may affect the macrocolony phenotype on the genetic/epigenetic level/s (e.g., down-regulation of structural genes involved in the biosynthesis of cellulose; a changed mode of the signaling molecules activation capacity; changes in methylation/demethylation patterns in yeasts etc.), on the level of BC synthesis (e.g., a lack of divalent cations or a signaling molecule cyclic-diguanylate-GMP) or on the cellular level (cell outer membrane desintegration by eDNA or bacteriophages).

When we think about signatures of life beyond earth we anticipate a protein-nucleic acid-based life similar to the terrestrial life capable to create self-related entities. Following this Earth-like direction, it is important to select biosignatures among a big variety of organic molecules, which appeared billions years ago. Microorganisms offer such signatures, being probable 'seeds' of life in the Universe (Cohn 1872). Bacterial cellulose is a widespread three-dimensional matrix for a biofilm formation in multimicrobial communities (Ross et al. 1991), and it is presumably one of the oldest native fossil macromolecules found on Earth (Griffith et al. 2008 ). The cellulose-based biofilm protects microbial inhabitants from environmental challenges (Costerton et al. 1995; Welch et al. 2005; Kato et al. 2007). Our data on the high-speed electron irradiations show that dehydrated film was highly robust. The radiation field encountered in the LEO environment is weaker than we modeled (Dachev et al. 2015), however, the structure of the cellulose polymer molecule practically did not change under model experiments. 
In natural settings, this exopolymer molecule could be modified by inorganic inclusions and might be rather stable under extreme conditions of early life on our planet. In this study, we showed that inorganic ions bioleached from anorthosite, provided the rigidness of the biofilms and probably affected a social life and protection of the community from extrinsic stressors.

\section{Biomobilization of Inorganic Ions by Microbial Community-Members from Anorthosite Rock and Accumulation in the Cellulose-Based Pellicle}

Anorthosite used in this study is aluminosilicate rock, where $\mathrm{SiO}$ and $\mathrm{Al}_{2} \mathrm{O}_{3}$ comprise more than $70 \%$, and another elements are represented as $\mathrm{Fe}, \mathrm{Ca}$, $\mathrm{Mn}, \mathrm{Zn}, \mathrm{Cu}, \mathrm{Mg}$ etc. (Mytrokhyn et al. 2008). The main rock-forming minerals of lunar anorthosites are calcium-containing plagioclase $\mathrm{Ca}\left[\mathrm{Al}_{2} \mathrm{Si}_{2} \mathrm{O}_{8}\right]$, pyroxene $(\mathrm{Mg}, \mathrm{Fe}, \mathrm{Ca})(\mathrm{Mg}, \mathrm{Fe})\left[\mathrm{Si}_{2} \mathrm{O}_{6}\right]$, and olivine $(\mathrm{Mg}, \mathrm{Fe})_{2}\left[\mathrm{SiO}_{4}\right]$ (Ashwal 1993 ). In the mineral-water interface, multiple reactions occur, such as adsorption, dissolution-precipitation, redox, and photocatalysis, depending on mineral variety, cells/molecules involved and environmental conditions. Microorganisms modify rates and mechanisms of these reactions, e.g., chemical and physical weathering. For example, the rate of bacterial oxidation of ferrous iron released from pyrite surfaces is up to one million times faster than the inorganic oxidation rate (Singer and Stumm 1970). The microorganisms directly or indirectly induce mineral disaggregating, hydration, dissolution, secondary mineral formation and can radically modify the dissolution rates of silicates. Microbial organisms (lithotrophs) derive their metabolic energy from inorganic substrates (e.g., $\mathrm{Mn}^{+2}, \mathrm{Fe}^{+2}$, S etc.) (Natarajan et al. 1997; Rohwerder et al. 2003). In our earlier experiments on bioleaching of inorganic ions from anorthosite in a two-phase system (cultural liquid - rock), results showed that the microbial organisms released elements from the rock and accumulated either on/in microbial cells or biofilm (Zaets et al. 2011, 2014). Microbial solubilization and the breakdown of minerals can be caused by a wide range of microbial extracellular metabolites such as organic acids and exopolysaccharides, siderophores, which kombucha community-members produce, consuming carbohydrates. In natural settings, adapted consortia of indigenous microorganisms employ the bioleaching mechanisms to derive energy from organo-minerals (Włodarczyk et al. 2015) $)$, our earlier and present results showed highly effective adaptation capacity of domesticated 
microbial community.

Bioleaching may cause a toxicity in the microenvironment for certain microbial community-members; in addition to the toxicity of soluble ions, the high dose of accumulated nanoparticles affect the microniche. It was shown that anorthosite-forming minerals such as pyrite, olivine, and pyroxene may cause nucleic acid degradation via surface free radicals generated (Xu et al. 2013) and promote rupture of lipid vesicles (Xu et al. 2009).

In this study, the SEM-EDX microanalysis showed that BC-based membranes were mineralized with the excess of metal cations and nanoparticles, when produced by KMC in the presence of anorthosite. The mobility of $\mathrm{Mg}, \mathrm{Fe}, \mathrm{K}, \mathrm{Al}$, Si from anorthosite to pellicle under assistance of KMC-members observed during the batch experiment. The extensive growth of the $\mathrm{SiO}_{2}$ group of secondary minerals on the bottom surface of pellicle unequivocally documented primary dissolution of the silica-rich minerals in the anorthosite rock and accumulation on/in pellicle. Mineral deposits may serve as a source of elements, e.g., the iron, that could be used in future times of iron starvation. The mineral inclusions affected the structure of BC polymer. It was seen in changed IR-spectra, e.g., in a sharper peak in a region corresponding to - $\mathrm{OH}$ stretching vibrations, which could indicate that $\mathrm{OH}$ groups were engaged in $\mathrm{BC}$ interaction with inorganic ions and in the formation of the complex with metals. On the other hand, nanoparticles and secondary minerals mechanically covered the bottom surface of cellulose matrix (see Fig. 2a). The mineral crust formed by microorganisms on the biofilm surface has partially shielded the absorption capacity of mineralized cellulose. The enhanced metalome (i.a., the entire set of the metal ions in a given compartment) protected the bacterial kombucha community-members in a form of mineral crust against a low-dose UV.

Biomineralization affected the KMC structure. RAPD-community analysis data provided evidence that $\mathrm{KMC}$ undergone adaptive changes in response to dysregulated mineral metabolism. These adaptations could initially promote survival but ultimately culminated in changes of the KMC structure and overt cellulose mineralization.

Within 3D Cellulose Matrix There are Extracellular 


\section{Components Which May Affect the Cellulose Formation and Integrity of Biofilm}

In the polychromatic UV-treated kombucha culture, both partial bacterial cell lysis and biofilm degradation were observed, and this might be explained with known phenomenon of the activation of prophages in lysogenic bacterial community-members by UV (Canchaya et al. 2003). Actually, after UV irradiation, rare phage particles were observed, which appeared scavenged by OMVs (Kharina et al. 2015). Probably, in this case, extracellular membrane vesicles played a role of the stabilizer of celluloseforming bacterial populations because pellicle damage was not complete, and after a short period of time the community was restored. OMVs are produced by Gram-negative bacteria via 'budding' of a portion of outer membrane from bacterial cell and released as nano-sized spheres (20$300 \mathrm{~nm}$ ) (see Kulkarni et al. 2014). The chemical or physical stressors (e.g., antibiotics, osmotic pressure, or heat shock) increase the production of OMVs without any increase in cell lysis (MacDonald and Kuehn 2013; Schwechheimer and Kuehn 2015). OMVs have also been identified as a stress response that can remove from bacterial cells misfolded proteins (Manning and Kuehn 2011) and probably damaged DNA during the repair of genome after exposure to radiation. Except bacterial OMVs, the KMC yeast component produce extracellular membrane vesicles such as PGV (will be published).

We have detected the increased level of EMVs produced in the KMC grown with anorthosite, and this correlated with the increased level of elements accumulated in pellicle. Superproduction of nanovesicles seems to be an adaptation reaction of $\mathrm{KMC}$ on toxic concentrations of bioleached elements from anorthosite.

Extracellular membrane vesicles-mineral interactions were described in biomineralization of amorphous silica by diatoms, calcite spicules by sponges, magnetite by bacteria, calcium oxalate and vascular calcification in humans, etc., where precipitation occured within a volume of space defined by phospholipid membranes, in other words, within EMVs (Boskey 1986; Hutcheson et al. 2014; Shapiro et al. 2015). Xu et al. (2009) substantiated the interactions of amphiphilic molecules with mineral surfaces in diverse processes, including membrane-bound biomineralization. Role of OMVs in biomineralization reactions on biowethering of 
aluminosilicate rock has been described by Matlakowska et al. (2012). We have found $\mathrm{Al}$ and $\mathrm{Fe}$ in the pure preparations of EMVs isolated from $\mathrm{KMC}$ grown in the presence of anorthosite (will be published).

A possible benefit of the production of OMVs in the environment and participation in the biomineralization of elements is an important environmental implication for mineral depositions. In a wider sense, extracellular vesicles or nanoglobules are intriguing objects in astrobiological discussions about origin of life and Lithopanspermia (McKay et al. 1996; Kebukawa et al. 2009; De Gregorio et al. 2013; Gill and Forterre 2016).

\section{Lessons from Laboratory Simulations and Experience Gained from Literature}

1) Mineral crust and nanoparticles formed by bioleached ions cover a surface of the cellulose-based pellicle, and cellulose molecules change in the presence of inorganics. However, the modification does not relate to the $\beta(1,4)$ - linkage which vibrations can be detected by the IR-signature band for cellulose $-897 \mathrm{~cm}^{-1}$.

2) Mineralization protects the cellulose-based film from degradation. We may predict that in natural settings, this molecule embedded with inorganic ions might be rather stable under extreme conditions.

3) The excess of inorganic ions changes the KMC structure, however, a core microbial organism survived. We may expect that after an inorganic stress, epigenetically changed key KMC-members will have better survival capacity.

4) Presence of microbial cells and EMVs in pellicles gives additional biomarkers (DNA, proteins, cell surface structures) which can be fossilized within the cellulose nanonetwork.

5) Extracellular components of the KMC pellicle shape the KMC macrocolony. We may predict extracellular biofilm constituents, e.g., EMVs, can cause the post-irradiation effect on microbial populations and its progeny and perpetuate delayed genetic instability in KMC (Al-Mayah et al. 2015). 


\section{References}

Al-Mayah A, Bright S, Chapman K, Irons S, Carter D, Goodwin E, Kadhim M (2015) The non-targeted effects of radiation are perpetuated by exosomes. Mutat Res 772:38-45. doi:

10.1016/j.mrfmmm.2014.12.007

Ashwal LD (1993) Anorthosites, vol 21, Minerals and rocks series. Springer-Verlag, Berlin, 422 pp

Binnenkade L, Teichmann L, Thormann KM (2014) Iron triggers $\lambda$ So prophage induction and release of extracellular DNA in Shewanellaoneidensis MR-1 biofilms. Appl Environ Microbiol 80(17):5304-5316. doi: 10.1128/AEM.01480-14

Boskey AL (1986) In: Ali SY (ed) Cell mediated calcification and matrix vesicles. Elsevier, Amsterdam, pp 175-179

Brenner G (1997) Bergey's manual of systematic bacteriology. Williams and Wilkins, NewYork

Canchaya C, Proux C, Fournous G, Bruttin A, Brüssow H (2003) Prophage genomics. Microbiol Mol Biol Rev 67(2):238-276. doi: 10.1128/MMBR.67.2.238-276.2003

Chawla PR, Bajaj IB, Survase SA, Singhal RS (2009) Microbial cellulose: fermentative production and applications. Food Technol Biotechnol 47(2):107-124

Cohn F (1872) Überbakterien, die kleinstenlebenden Wesen. Berlin

Cohn F (1876) Untersuchungenüber Bacterien. IV. Beiträgezur Biologie der Bacillen. In: Beiträgezur Biologie der Pflanzen 7:249-267

Costerton JW, Lewandowski Z, Caldwell DE, Korber DR, Lappin-Scott 
HM (1995) Microbial biofilms. Annu Rev Microbiol 49:711-745. doi: 10.1146/annurev.mi.49.100195.003431

Dachev T, Horneck G, Häder DP, Schuster M, Lebert M (2015) EXPOSE-R cosmic radiation time profile. Int J Astrobiol 14(1):17-25. doi: $10.1017 / \mathrm{S} 1473550414000093$

de Gregorio BT, Stroud RM, Nittler LR, Alexander CMOd, Bassim ND, Cody GD, Kilcoyne ALD, Sandford SA, Milam SN, Nuevo M, Zega TJ (2013) Isotopic and chemical variation of organic nanoglobules in primitive meteorites. Meteorit Planet Sci 1-25. doi:

10.1111/maps.3/15/201612109

de Vera JP, Boettger U, de la Torre Noetzel R et al (2012) Supporting Mars exploration: BIOMEX in Low Earth Orbit and further astrobiological studies on the Moon using Raman and PanCam technology. Planet Space Sci 74(1):103-110. doi:

10.1016/j.pss.2012.06.010

Echeverrigaray S, Paese-Toresan S, Carrau JL (2000) RAPD marker polymorphism among commercial winery yeast strains. World J Microbiol Biotechnol 16:143-146. doi: 10.1023/A:1008993129713

Flemming HC, Wingender J (2010) The biofilm matrix. Nat Rev Microbiol 8:623-633. doi: 10.1038/nrmicro2415

Franklin RB, Taylor D, Mills A (1999) Characterization of microbial communities using randomly amplified polymorphic DNA (RAPD). J Microbiol Methods 35:225-235

Gill S, Forterre P (2016) Origin of life: LUCA and extracellular membrane vesiscles (EMVs). Int J Astrobiol 15(1):7-15. doi: $10.1017 / \mathrm{S} 1473550415000282$

Griffith JD, Willcox S, Powers DW, Nelson R, Baxter BK (2008) Discovery of abundant cellulose microfibers encased in 250 Ma Permian halite: a macromolecular target in the search for life on other planets. Astrobiology 8(2):215-228. doi: 10.1089/ast.2007.0196 
Gudipati MS, Rui Y (2012) In-situ probing of radiation-induced processing of organicsin astrophysical ice analogs - novel laser desorption laser ionization time-of-flight mass spectroscopic studies. Astrophys J Lett 756:L24. doi: 10.1088/2041-8205/756/1/L24

Hegdea S, Paulino-Limab IG, Kentc R, Kaltenegger L, Rothschild L (2015) Surface biosignatures of exo-Earths: remote detection of extraterrestrial life. PNAS 112(13):3886-3891. doi:

$10.1073 /$ pnas. 1421237112

Hestrin S, Schramm M (1954) Synthesis of cellulose by Acetobacter xylinum. 2. Preparationof freeze-dried cells capable of polymerizing glucose to cellulose. Biochem J 58:345-352

Hutcheson JD, Goettsch C, Pham T, Iwashita M, Aikawa M, Singh SA, Aikawa E (2014) Enrichment of calcifying extracellular vesicles using density-based ultracentrifugation protocol. J Extracell Vesicles. doi: 10.3402/jev.v3.25129

Igisu M, Nakashima S, Ueno Y, Awramik SM, Maruyama S (2006) In situ infrared microspectroscopy of 850 million-year-old prokaryotic fossils. Appl Spectrosc 60:1111-1120. doi:

$10.1366 / 000370206778664707$

Jayabalan R, Malbasa R, Loncar E, Vitas J, Sathishkumar M (2014) A review on kombucha tea-microbiology, composition, fermentation, beneficial effects, toxicity, and tea fungus. Compr Rev Food Sci Food Saf 13:538-550. doi: 10.1111/1541-4337.12073

Johnson DB, Hallberg KB (2003) The microbiology of acidic mine waters. Res Microbiol 154:466-473. doi: 10.1016/S09232508(03)00114-1

Kato N, Sato T, Kato S et al (2007) Viability and cellulose synthesizing ability of Gluconacetobacter xylinus cells under highhydrostatic pressure. Extremophiles:11(5):693-698. doi: 10.1007/ s00792-007-0085-y 
Kebukawa Y, Nakashima S, Nakamura-Messenger K, Zolensky ME (2009) Submicron distribution of organic matter of carbonaceous chondrite using near-field infrared microspectroscopy. Chem Lett 38(1):22-23. doi: 10.1246/cl.2009.22

Kharina A, Podolich O, Faidiuk I, Zaika S, Haidak A, Kukharenko O, Zaets I, Tovkach F, Reva O, Kremenskoy M, Kozyrovska N (2015) Temperate bacteriophages collected by outer membrane vesicles in Komagataeibacter intermedius. J Basic Microbiol 55(4):509-513. doi: 10.1002/jobm.201400711

Kukharenko O, Podolich O, Rybitska A, Reshetnyak G, Burlak L, Ovcharenko L, Voznyuk T, Moshynets O, Rogutskyi I, Zaets I, Yaneva O, Pidgorskiy V, Rabbow E, de Vera JP, Kozyrovska N (2012) Robust symbiotic microbial communities in space research. In: Fedorov OP (ed) Space research in Ukraine (2010-2011). The report to the COSPAR. AcademPeriodyka, Kyiv, pp 102-105

Kulkarni HM, Swamy CVB, Jagannadham MV (2014) Molecular characterization and functional analysis of outer membrane vesicles from the antarctic bacterium Pseudomonas syringae suggest a possible response to environmental conditions. J Proteome Res 13:1345-1358. doi: $10.1021 / \mathrm{pr} 4009223$

Lee LH, Cheah YK, Syakima AMN, Shiran MS, Tang YL, Lin HP, Hong K (2012) Analysis of Antarctic proteobacteria by PCR fingerprinting and screening for antimicrobial secondary metabolites. Genet Mol Res 11(2):1627-1641. doi: 10.4238/2012

Lee KWK, Periasamy S, Mukherjee M, Xie C, Kjellebergand S, Rice SA (2014) Biofilm development and enhanced stress resistance of a model, mixed-species community biofilm. ISME J 8:894-907. doi:

10.1038/ismej.2013.194

Li Y, Ying Y, Zhao D, Ding W (2012) Microbial community diversity analysis of Panax ginseng rhizosphere and non-rhizosphere soil using randomly amplified polymorphic DNA method. Open J Genet 2:95-102. doi: 10.4236/ojgen.2012.22014 
Liu J, Prindle A, Humphries J, Gabalda-Sagarra M, Asally M, Lee DD, Ly S, Garcia-Ojalvo J, Suel GM (2015) Metabolic co-dependence gives rise to collective oscillations within biofilms. Nature. doi:

10.1038 /nature 14660

MacDonald JA, Kuehn M (2013) Stress-induced outer membrane vesicle production by Pseudomonas aeruginosa. J Bacteriol 195(13):2971-2981. doi: 10.1128/JB.02267-12

Maier RM, Drees KP, Neilson JW, Henderson DA, Quade J, Betancourt JL (2004) Microbial life in the Atacama desert. Science 306:1280. doi: 10.1126/science.306.5700.1289c

Manning AJ, Kuehn MJ (2011) Contribution of bacterial outer membrane vesicles to innate bacterial defense. BMC Microbiol 11:258262. doi: $10.1186 / 1471-2180-11-258$

Matlakowska R, Skłodowska A, Nejbert K (2012) Bioweathering of Kupferschiefer black shale (Fore-Sudetic Monocline, SW Poland) by indigenous bacteria: implication for dissolution and precipitation of minerals in deep underground mine. FEMS Microbiol Ecol 81:99-110. doi: 10.1111/j.1574-6941.2012.01326.x

McKay DS, Gibson EK Jr, Thomas-Keprta KL, Vali H, Romanek CS, Clemett SJ, Chillier X, Maechling CR, Zare RN (1996) Search for past life on Mars: possible relic biogenic activity in martian meteorite ALH84001. Science 273:924-930. doi: 10.1126/science.273.5277.924

Miller JH (1972) Experiments in molecular genetics. Cold Spring Harbor Laboratory, Cold Spring Harbor

Musk DJ, Banko DA, Hergenrother PJ (2005) Iron salts perturb biofilm formation and disrupt existing biofilms of Pseudomonas aeruginosa.

Chem Biol 12:789-796. doi: 10.1016/j.chembiol.2005.05.007 
Mytrokhyn OV, Bogdanova SV, Shumlyanskyy LV (2008)

Polybaricchrystalization of Korosten plytonanortosites (Ukrainian shield). Mineral J 30:36-56

Natarajan KA, Modak JM, Anand P (1997) Some microbiological aspects of bauxite mineralization and beneficiation. Miner Metall Process 14:47-53

Noffke N (2015) Ancient sedimentary structures in the $<3.7$ Ga Gillespie lake member, Mars, that compare in macroscopic morphology, spatial associations, and temporal succession with terrestrial microbialites. Astrobiology 15(2):169-192. doi: 10.1089/ast.2014.1218

Ordax M, Marco-Noales E, López M, Biosca E (2006) Survival strategy of Erwinia amylovora against copper: induction of the viable-butnonculturable state. Appl Environ Microbiol 72(5):3482-3488. doi: 10.1128/AEM.72.5.3482-3488.2006

Parnell J, Cullen D, Sims MR, Bowden S, Cockell CS, Court R, Ehrenfreund P, Gaubert F, Grant W, Parro V, Rohmer M, Sephton M, Stan-Lotter H, Steele A, Toporski J, Vago J (2007) Searching for life on Mars: selection of molecular targets for ESA's Aurora ExoMars mission. Astrobiology 7(4):578-604. doi: 10.1089/ast.2006.0110

Paul JH (2008) Prophages in marine bacteria: dangerous molecular time bombs or the key to survival in the seas? ISME J 2:579-589. doi: 10.1038/ismej.2008.35

Qiu K, Netravali AN (2014) A review of fabrication and applications of bacterial cellulose based nanocomposites. Polym Rev 54(4):598-626. doi: $10.1080 / 15583724.2014 .896018$

Reva ON, Zaets IE, Ovcharenko LP, Kukharenko O, Shpylova S, Podolich OV, de Vera JP, Kozyrovska NO (2015) Metabarcoding of the kombucha microbial community grown in different microenvironments. AMB Express 5:35-42. doi: 10.1186/s13568-015-0124-5

Rohwerder T, Gehrke T, Kinzler K et al (2003) Bioleaching review part A: progress in bioleaching: fundamentals and mechanisms of bacterial 
metal sulfide oxidation. Appl Microbiol Biotechnol 63:239-248. doi: $10.1007 / \mathrm{s} 00253-003-1448-7$

Romling U (2002) Molecular biology of cellulose production in bacteria. Res Microbiol 153:205-212. doi: 10.1016/S0923-2508(02)01316-5

Ross P, Mayer R, Benzimann M (1991) Cellulose biosynthesis and functions in bacteria. Res Microbiol 153:205-212

Schwechheimer C, Kuehn MJ (2015) Outer-membrane vesicles from Gram-negative bacteria: biogenesis and functions. Microbiology 13:605619. doi: $10.1038 /$ nrmicro3525

Schwieterman EW, Cockell CS, Meadows VS (2015) Nonphotosynthetic pigments as potential biosignatures. Astrobiology 15(5):341-361. doi: 10.1089/ast.2014.1178

Seager S, Bains W (2015) The search for signs of life on exoplanets at the interface of chemistry and planetary science. Sci Adv. doi: 10.1126/sciadv. 1500047

Shapiro IR, Landis WJ, Risbud M (2015) Matrix vesicles: are they anchored exosomes? Bone 79:29-36. doi: 10.1016/j.bone.2015.05.013

Simoneit BRT, Summons RE, Jahnke LL (1998) Biomarkers as tracers for life on early earth and mars. Orig Life Evol Biosph 28:475-483. doi: 10.1023/A:1006508012904

Singer PC, Stumm W (1970) Acid mine drainage: the rate-determining step. Science 167:1121-1123

Thiel CS, Ehrenfreund P, Foing B, Pletser V, Ullrich O (2011) DNA, PCR-based analysis of microbial communities during the EuroGeoMars campaign at Mars Desert Research Station, Utah. Int J Astrobiol 10:177190. doi: 10.1017/S1473550411000073

Varnali T, Edwards H (2013) A potential new biosignature of life in iron-rich extreme environments: an iron (III) complex of scytonemin and proposal for its identification using Raman spectroscopy. Planet Space 
Wang X, Kim YMQ, Hong SH, Pokusaeva K, Sturino JM, Wood TK (2010) Cryptic prophages help bacteria cope with adverse environments. Nat Commun 1:147. doi: 10.1038/ncomms 1146

Welch M, Mikkelsen H, Swatton JE, Smith D, Thomas GL, Glansdorp FG, Spring DR (2005) Cell-cell communication in Gram-negative bacteria. Mol BioSyst 1(3):196-202. doi: 10.1039/b505796p

Westall F, Steele A, Toporski J, Walsh M, Allen C, Guidry S, McKay K, Gibson E, Chafetz H (2000) Polymeric substances and biofilms as biomarkers in terrestrial materials: implications for extraterrestrial samples. J Geophys Res 105(10):24511-24527. doi:

10.1029/2000JE001250

Williams JGK, Kubelik AR, Livak KJ, Rafalski JA, Tingey SV (1990) DNA polymorphisms amplified by arbitrary primers are useful as genetic markers. Nucleic Acid Res 18:6531-6535. doi: 10.1093/nar/18.22.6531

Włodarczyk A, Stasiuk R, Skłodowska A, Matlakowska R (2015) Extracellular compounds produced by bacterial consortium promoting elements mobilization from polymetallic Kupferschiefer black shale (Fore-Sudetic Monocline, Poland). Chemosphere 122:273-279. doi: 10.1016/j.chemosphere.2014.11.073

Xu J, Stevens MJ, Oleson TA, Last JA, Sahai N (2009) Role of oxide surface chemistry and phospholipid phase on adsorption and selfassembly: Isotherms and atomic force microscopy. J Phys Chem 113:2187-2196. doi: 10.1021/jp807680d

Xu J, Sahai N, Eggleston CM, Schoonen MA (2013) Reactive oxygen species at the oxide/water interface: formation mechanisms and implications for prebiotic chemistry and the origin of life. Earth Planet Sci Lett 363:156-167. doi: 10.1016/j.eps1.2012.12.008

Yu X, Atalla RH (1996) Production of cellulose II by Acetobacter xylinum in the presence of 2,6-dichlorobenzonitrile. Int J Biol Macromol 19:145-146. doi: 10.1016/0141-8130(96)01109-9 
Zaets I, Burlak O, Rogutskyy I, Vasilenko A, Mytrokhyn O, Lukashov D, Foing B, Kozyrovska N (2011) Bioaugmentation in growing plants for lunar bases. Adv Space Res 47:1071-1078. doi:

10.1016/j.asr.2010.11.014

Zaets I, Podolich O, Kukharenko O, Reshetnyak G, Shpylova S, Sosnin M, Khirunenko L, Kozyrovska N, de Vera JP (2014) Bacterial cellulose may provide the microbial-life biosignature in the rock records. Adv Space Res 53(5):828-835. doi: 10.1016/j.asr.2014.01.002 